\title{
Computer Aided Pesticide Design: A Rational Tool for Supplementing DDT Lacunae
}

\author{
VANDANA SAINI and AJIT KUMAR* \\ Toxicology \& Computational Biology Group, \\ Centre for Bioinformatics, M.D. University, Rohtak, India \\ akumar.cbt.mdu@gmail.com
}

Received 7 September 2013 /Accepted 6 October 2013

\begin{abstract}
The reliance of mankind on synthetic pesticide, particularly dichloro diphenyl-trichloro ethane (DDT) reached its zenith during 1950s-60s, since the first application during second world War. But very soon it faced a serious scientific opposition due to its bio-magnifying nature and was banned in 1970s in most part of world with certain exceptional usage in health control programmes. Although, the pesticidal activity range and economic viability of DDT has never been questioned and still there are several voices to bring back DDT. To answer this controversy is the search for new DDT like pesticide with similar pesticidal efficacy and lower ecological accumulative effects. Recent advances in computer aided molecular design has provided us very robust, economic and time and labour saving tool to design and develop new chemical entities with pesticidal activity similar to DDT and has good commercial prospects as well. The present paper reviews the brief history of DDT and the developments in computational and molecular design methods to rejuvenate the era of new pesticide research.
\end{abstract}

Keywords: DDT, Molecular modelling, Pesticide design, Voltage gated sodium channel

\section{Introduction}

Pesticides are economic, labour-saving, and efficient tool of pest management with great popularity in most sectors of the agricultural production and health control programmes. In spite of their popularity and extensive use, health risks arising from the exposure of farmers when mixing and applying pesticides or working in treated fields and from residues in food and in drinking water for the general population have been raised, making it a necessary evil in modern agricultural and pest management practices.

Pesticides are chemically classified into four categories namely, organochlorine (OC), organophosphate, carbamate and pyrethroid pesticides. OC pesticides are the oldest developed pesticides which mainly affect sodium channels by preventing the deactivation or closing of channels after activation and membrane depolarisation. The hyper excitability results in repetitive discharges in neuron after a single stimulus ${ }^{1}$. Many of OC pesticides (DDT, BHC etc.) were commonly used in the past, but have been removed from the market because of environmental and health risks ${ }^{2}$. As far as their biological activity is concerned 
against target organisms, OCs showed very good results but were banned worldwide because of their toxic effects due to biomagnification in food chain and their persistence in environment.

\section{DDT: A wonder pesticide}

DDT, an OC pesticide, was first synthesized by Zeidler in 1874 but it was used as an insecticide in the year $1939^{3}$. DDT is 1,1,1-trichloro-2,2-bis-( $p$-chlorophenyl) ethane with chemical formula $\mathrm{C}_{14} \mathrm{H}_{9} \mathrm{Cl}_{5}$. So, for every molecule of DDT, there are 14 carbon atoms, 9 hydrogen atoms and 5 chlorine atoms (Figure 1). In its pure form, DDT is a white, crystalline powder with little odour. DDT's long life is due to its low solubility in water and it's relatively high solubility in fats.

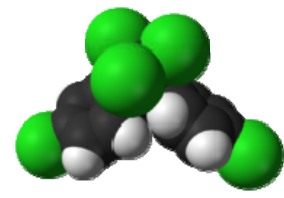

[a]

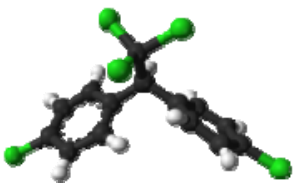

[b]

Figure 1. Space fill model [a] and Ball \& Stick model [b] of DDT

After the discovery that DDT can be used against insects, it was extensively used by almost all the countries around the world for agriculture and health programs. DDT played heroic role not only during green revolution in India but also in other countries in increasing the agricultural productivity and in controlling vector borne epidemics. DDT is the most recognized insecticides all over the world due to the fact that its use has helped reveal the numerous hazards coupled with the use of synthetic pesticides. DDT is a colorless, odorless, and insoluble toxic pesticide which contains about fourteen chemical substances in it. This chemical is known for eradicating and destroying harmful insects like flies, mosquitoes, and lice. It is also widely used to kill agricultural pests. The many benefits of DDT include:

\section{Disease control}

DDT has been used to kill organisms that are responsible for causing malaria, filariasis and dengue fever. The use of this disinfectant has probably saved the lives of about 50 million people from these diseases ${ }^{4}$.

\section{Effective for long periods}

DDT is highly persistent and continues to be effective in killing disease causing mosquitoes for months after being applied ${ }^{5}$.

\section{Beneficial for plants}

As water spray or crop dust DDT has been routinely used on orchards, fields, gardens, and forests. There was time when the use of this chemical had increased so much that it was registered to be used on more than 300 agricultural crops all over the world ${ }^{6}$.

\section{Durable in nature}

DDT is highly durable in nature and in some of its applications it is effectual for more than 12 years. This chemical cannot be easily washed by water and it also resists breakdown by air and light ${ }^{7}$.

\section{Low price}

This chemical is quite cheap and can be afforded by all to kill any kind of insects and pests ${ }^{8}$. 


\section{Low toxicity to humans}

The chemical is highly toxic to bugs and insects, but has very low toxicity to all mammals including humans. Thus, this chemical can be directly applied to the human skin for killing parasites without causing harm to the person using $\mathrm{it}^{7,8}$.

DDT-A tonic...or toxin?

Since Rachel Carson's Silent Spring, conservationists in rich, developed countries have waged a decades-long campaign, no less persistent than DDT itself, to convince governments and citizens that DDT is an irredeemable pollutant. They have been very successful: Every industrial country, without exception, has ceased using DDT ${ }^{9}$.

In this kind of 'balance of risks' paradigm, the evidence must be scrupulously weighed. Although the International Agency for Research on Cancer rates DDT as a possible human carcinogen (along with, notably, several pharmaceutical drugs), not one case-control study of DDT's human carcinogenicity has been affirmatively replicated. Breast cancer furnishes the clearest example: the first study to correlate DDT exposure with statistically elevated risk ${ }^{10}$ has now failed to be replicated at least 8 times $^{11-18}$ and of these later studies, some found exposure to significantly reduce risk $^{17,18}$. Much the same can be said of studies indicating involvement of DDT in multiple myeloma, hepatic cancer and non-Hodgkin lymphoma ${ }^{19-20}$.

Indeed, if precaution is relevant, it favours spraying houses with DDT, because it is affordable or effective where other interventions may not be. Cost data from India show that, even using DDT alone, the entire national malaria-control budget is sufficient to protect only $65 \%$ of high-risk persons. Switching to malathion, the next-cheapest alternative, reduces that coverage to $21 \%$, which leaves 71 million more persons unprotected ${ }^{21}$. House spraying also has the advantage that it protects whole families, which is sometimes overlooked in comparing it with insecticide-treated bed-nets, which protect only one or two people at a time $^{22}$. Simply put, there are too few economic studies to determine with certainty whether bed-nets are more or less cost-effective than DDT house spraying ${ }^{23}$.

The debate about the rationality of DDT usage may continue further, but a fact remains unquestioned at its place that it is the most economic synthetic pesticide which has changed the perception of uncontrollable vector borne diseases and agricultural yield increase, because of its mode of action. Also, the fact remains true that everything can wait but hunger cannot.

\section{Mode of action of DDT}

The voltage-gated sodium channel (VGSC) is the target site for insecticides such as DDT and synthetic pyrethroids ${ }^{24}$. The mode of action of DDT was investigated in the homology model of VGCS generated for house fly, Musca domestica L. using docking simulation studies. Binding studies demonstrated the existence of membrane receptors which bind specifically to DDT. The receptors show properties to be expected of a critical target site of these insecticides ${ }^{25}$. DDT affects mainly the peripheral nervous system, initial contact with the insecticide causing neurons to fire spontaneously causing muscles to twitch, with resulting tremors throughout the body and appendages, the so-called 'DDT jitters'. Eventually, over the course of a few hours or days, DDT exposure leads to excitatory paralysis and consequent death of the insect. Compared with some insecticides DDT is rather slow acting. Its effects at a neuromuscular junction are brought about by depolarization due to an increased frequency of miniature post-synaptic potentials due to an accelerated spontaneous release of neurotransmitter. If depolarization continues the neuromuscular junction becomes blocked due to depletion of neurotransmitter ${ }^{25}$. The resistance of DDT in target pests has also been attributed to the $\mathrm{VGSCs}^{24,26}$. 


\section{Voltage gated sodium channel}

Voltage gated sodium channels are integral membrane proteins that form ion channels, conducting sodium ions $\left(\mathrm{Na}^{+}\right)$through a cell's plasma membrane $e^{27,28}$. They are classified according to the trigger that opens the channel for such ions, i.e. either a voltage-change ("Voltage gated", "voltage sensitive" or "voltage dependant" sodium channel also called "VGSCs" or "Nav channel") or binding of a substance (a ligand) to the channel (ligandgated sodium channels).In excitable cells such as neurons, myocytes and certain types of glia, sodium channels are responsible for the rising phase of action potentials.

The $\alpha$-subunit has four repeat domains, labelled I through IV, each containing six membrane-spanning segments, labelled S1 through S6 (Figure 2). The highly conserved S4 segment acts as the channel's voltage sensor. The voltage sensitivity of this channel is due to positive amino acids located at every fourth position. When stimulated by a change in transmembrane voltage, this segment moves toward the extracellular side of the cell membrane, allowing the channel to become permeable to ions. The ions are conducted through a pore, which can be broken into two regions. The more external (i.e., more extracellular) portion of the pore is formed by the "P-loops" (the region between S5 and S6) of the four domains ${ }^{29}$. This region is the narrowest part of the pore and is responsible for its ion selectivity. The inner portion (i.e., more cytoplasmic) of the pore is formed by the combined S5 and S6 segments of the four domains. The region linking domains III and IV is also important for channel function. This region plugs the channel after prolonged activation, inactivating $\mathrm{it}^{30}$. DDT has been investigated to bind on the upper half of the cavity region between S4-S5 linker, S5 helix and S6 helix ${ }^{24,31}$. All these studies were based on the homology model insect VGSC constructed using the crystal structure of voltage gated potassium channel of insects and the studies were limited in themselves. But the x-ray crystallography solved crystal structure of closed bacterial VGSC was reported for the first time ${ }^{32}$ in 2011 and was followed by the report of open bacterial VGSC ${ }^{33}$. These latest reports of crystal structure solutions of VGSC have opened a gateway to several in-silico studies involving VGSCs including DDT action. Thus a new era of computer aided pesticide design beckons the pesticide chemists.

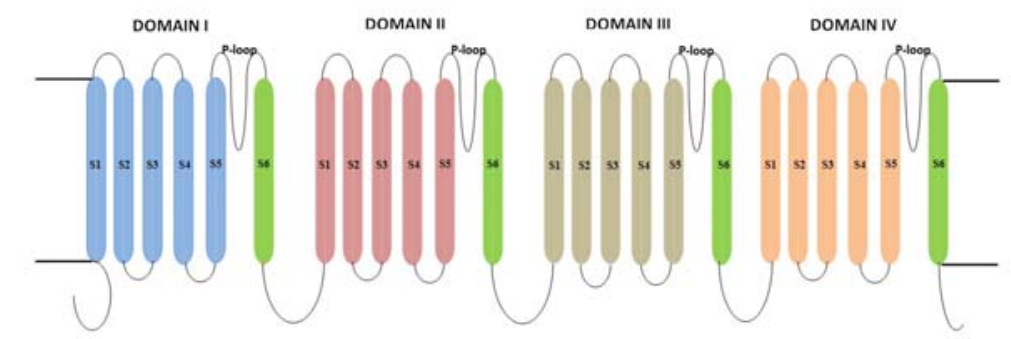

Figure 2. Trans-membrane topology of voltage gated sodium channel showing predicted binding sites of DDT (Adopted from Davies et al. ${ }^{3 l}$ )

\section{In-silico tools in pesticide design \& development}

Today throughout the world the principles of the 3R's are embedded in legislation which governs the ethical use of animals in science. 3R's represent - Replacement, Reduction and Refinement. In-silico tools have always been a very good alternative to replace animal experimentations. Also, the in-silico tools have always been at the central stage of drug and pesticide design and discovery. It is estimated that the Protein Data Bank (PDB) contains over 92,505 three-dimensional structures ${ }^{34}$. Advances in genomics and bioinformatics have allowed the identification of genes that code the primary sequences of hundreds of thousands 
of proteins, many of them being potential pharmacological targets. Several advances have been made in the field of proteomics (homology modeling, modeling protein folding, etc) to convert primary sequence information of biopolymers into 3D structural information. When advances in genomics, proteomics and molecular modeling are integrated, we obtain the 'from genome to drug' drug design protocols ${ }^{35,36}$.

The pharmacodynamic aspects, as well as the hardware and software tools employed in computer aided pesticide design are practically identical with those used in drug design, except for the pharmacokinetic considerations in the later ${ }^{37}$. The number of known experimental structures of pharmacological targets in the field of pesticide chemistry is significantly smaller than in medicinal chemistry ${ }^{38}$. Hence, pesticide chemists have to rely more upon indirect ligand based pesticide design methodologies. The major in-silico tools employed in pesticide design are - Virtual Screening, Molecular modelling, QSAR, Phylo-genomics and-proteomics, etc.

\section{Virtual screening}

Virtual screening (VS) has always been on the central stage of computational chemists and biologists. It is defined as automatically evaluating very large libraries of compounds using computer programs ${ }^{39}$. More practical vs. scenarios focus on designing and optimizing targeted combinatorial libraries and enriching libraries of available compounds from inhouse compound repositories or vendor offerings. The aim of virtual screening is to identify molecules of novel chemical structure that bind to the macromolecular target of interest. Thus, success of $v s$. is defined in terms of finding interesting new scaffolds rather than many of hits vs. has already a good success story in the field of medicinal chemistry ${ }^{40,41}$ and its usage in pesticide design and development is still in infancy.

\section{QSAR methodologies}

QSAR model are regarded as a scientifically efficient tool for predicting and classifying the biological activities of untested chemicals in both drug discovery and environmental toxicology ${ }^{42}$. QSAR decreases the number of compounds to be synthesized by facilitating the selection of most promising candidates. Developing scenario foretell the spread of QSAR beyond the pharmaceutical industry to human and environmental regulatory authorities for use in toxicology ${ }^{43}$. QSAR models are useful in research for purposes beyond prediction ${ }^{44}$. Existing structure-activity data provides insights into mechanism or identifying an alternative mechanism of action, identifying important structural characteristics, suggesting new design strategies and synthetic targets, narrowing the dose range for a planned assay, assisting in generation of new hypotheses to guide further research, and revealing chemicals that deviate from the QSAR model. Several successful QSARs have attracted the medicinal chemists to investigate the relationship of structural properties with biological activity ${ }^{45-47}$.

QSAR (Quantitative Structure Activity Relationship) relates the biological activity of molecule to some selected features of their physicochemical structure by means of a statistical tool. QSAR are based on the assumption that biological activity of a compound is related to its molecular properties. QSAR came into existence with works of Hansch et al. and Free et a ${ }^{48,49}$. Biological activity of congeneric molecular structures is related to specific molecular features (descriptors) by using regression techniques to estimate the relative importance of descriptors and their contribution to the biological activity. These physicochemical descriptors, which include parameters to account for hydrophobicity, topology, electronic properties, and steric effects, are determined empirically or, more recently, by computational methods. Various packages (e.g. $\mathrm{CODESSA}^{50}, \mathrm{DRAGON}^{51}, \mathrm{ALMOND}^{52}$ ) are available now a days for the calculation of large number of such descriptors. 
For the calculation of molecular descriptors used in QSAR, it is usually sufficient to generate the necessary structural information either from experimental methods (e.g., x-ray crystallography or nuclear magnetic resonance spectroscopy) or from calculations using molecular mechanics (MM). However, some descriptors (e.g., highest-occupied molecular orbital and the lowest-unoccupied molecular orbital energies) require calculations by quantum mechanics $(\mathrm{QM})$. To the best of our knowledge, few studies have attempted to compare the information content of the MM-based descriptors with that of the QM-based descriptors. Recently, Shi et $a l^{53}$., compared two structure-activity relationship models that employed different geometries (one MM calculated and another QM calculated) to calculate values for the same set of molecular descriptors. Variable selection in both cases was achieved using the Genetic Function Approximation ${ }^{54}$. A slightly better QSAR model was obtained for the QM-based descriptors than for the MM-based descriptors. The derived model is then used to analyze the results and to predict the activity of untested compounds. Effective descriptor selection, also known as variable selection, is an integral and inseparable part of the QSAR modeling process. In fact, most improvements in QSAR have been in the development and use of statistical approaches to make the selection of descriptors more effective.

Among various descriptor selection methods, GA approach has been particularly effective and efficient ${ }^{55}$. Genetic algorithm, as the name implies, is based on the principle of Darwinian evolution. A GFA approach developed by Rogers et al. ${ }^{56}$., is a popular GA-based statistical approach that is now widely used in QSAR model development. The overall process is repeated a lot of times until good combinations of descriptors are discovered and are dispersed throughout the population of QSAR models. An automated variable selection QSAR method based on the $k$-Nearest Neighbor $(k \mathrm{NN})$ principle was reported by Zheng and Tropsha ${ }^{57}$. The method was tested on a number of data sets demonstrating its effectiveness and generality. In this so-called $k \mathrm{NN}-\mathrm{QSAR}$ method, a chemical's activity is estimated as the mean activity value of its $k$ nearest neighbor based on Euclidean distance in a multidimensional descriptor coordinate system. A QSAR generally takes the form of a linear equation:

$$
\text { Biological Activity }=\text { Const }+(\mathrm{C} 1 \times \mathrm{P} 1)+(\mathrm{C} 2 \times \mathrm{P} 2)+(\mathrm{C} 3 \times \mathrm{P} 3)+\ldots . .+(\mathrm{Cn} \times \mathrm{Pn})
$$

Where the parameters $\mathrm{P} 1$ through $\mathrm{Pn}$ are computed for each molecule in the series and the coefficients $C 1$ through $\mathrm{Cn}$ are calculated by fitting variations in the parameters and the biological activity ${ }^{58}$.

QSAR models exist at the intersection of chemistry, statistics and biology. The development of a QSAR model requires three components: Dataset that provides experimental measures of biological activity for a group of chemicals.

a) Molecular structure or property data (descriptors, variables or predictors) for this group of chemicals.

b) Statistical methods to find relationship between these two datasets.

\section{Classification of QSAR Methodologies}

QSAR methods are categorized into following classes, based on the structural representation or the way by which the descriptor values are derived:

$>$ 2D QSAR correlates structures to their activity using molecular descriptors and ensemble of experimental data ${ }^{59}$.

> 3D QSAR correlates activity with non-covalent interaction fields. It allows simulation of directional forces, H-bonds, metal-ligand contacts ${ }^{60}$. 
$>$ 4D QSAR allows the multi-conformation orientation \& protonation state representation of ligand molecules so including ensemble of ligand configurations in $3 \mathrm{D} \mathrm{QSAR}^{61}$.

$>$ 5D QSAR includes multiple representations of induced-fit scenarios in 4D QSAR ${ }^{62}$.

$>\quad 6 \mathrm{D}$ QSAR incorporates different salvation models in 5D QSAR ${ }^{63}$.

\section{QSAR for biological activity prediction}

Knowledge of specific enzymes and reactive group of metabolic pathways may form the basis of various hypotheses in pesticide research. Measures of the activity of insecticides and the ability to predict their effects for organisms are useful for the development of QSARs. This advances our understanding of both the activity response and the factors controlling this response. If an active compound is detected by biological tests, then several of its derivatives are prepared. Computerized mathematical processing of data can reveal QSARs, on the basis of which the efficiency of compounds not yet prepared can be predicted with greater probability.

The organochlorine and synthetic pyrethroid insecticides are acute neurotoxic chemicals with major uses in public health, agriculture and forestry ${ }^{64}$. Structure-activity relationships were considered for each subclass by coats. Lipophilicity was found to be important for all the groups because it facilitates delivery of these neurotoxicants to the site of action in the nerve. Steric factors including molecular volume, shape and isomeric configuration greatly influence toxicity. Electronic parameters were demonstrated to affect biological activity in some of the groups of insecticides, e.g., Hammett's $\sigma$ and Taft's $\sigma$ as indicators of electronegativity. A possible approach to develop QSARs for reactive chemicals based on simple considerations regarding their reactivity was given by Verhaar et al., ${ }^{65}$. It was shown that quantum chemical calculations on reaction transition states can be used to quantitatively predict the reactivity of sets of reactive chemicals. These predictions can then be used to develop aquatic toxicity QSARs.

QSAR was devised for the neuropathy potency of various organophosphate (OP) compounds $^{66}$. Study describes QSAR for NTE inhibition and 'aging' in chick brain homogenate and human neuroblastoma cells exposed to the OP compounds. Earlier studies have suggested that the neuropathy potential of an OP insecticide is determined by measuring NTE inhibition and 'aging' in the brain homogenate or neuroblastoma cell cultures exposed to the OP insecticides ${ }^{67,68}$. Since a large number of OP insecticides are currently being used worldwide, experimental evaluation of the neuropathic potential of each compound individually may be time consuming and expensive. The aim of that study was to develop QSAR models that would accurately predict the neuropathy potential of OP compounds.

The biological effects of most organophosphate compounds (OP) are due to inhibition of the enzyme acetylcholinesterase (AChE). The 3D-quantitative structure- activity relationship (3D-QSAR) on the acute toxicity to housefly (Musca nobulo L.) of 35 dialkyl phenyl phosphate compounds are studied by using comparative molecular field analysis (CoMFA) and comparative molecular similarity index analysis (CoMSIA) methods. Study suggested that the combination of both approaches, can give more comprehensive and accurate perspectives on the mechanism of the reaction between $\mathrm{OP}$ and $\mathrm{AChE}^{69}$. The results showed that the length of alkyl and the electronegative of substituent on phenyl of OP have significant effects on the AChE activity, whereas, the hydrophobicity of OP has little influence. The steric and electronic properties of OP have a dominant influence on the reaction between OP and AChE.

Molecular modeling studies were performed on a collection of organophosphorous acetylcholinesterase inhibitors by the combined use of conformational analysis and 3DQSAR methods to rationalize their inhibitory potencies against the enzyme ${ }^{70}$. The Catalyst program was used to identify the structural features in the group of 8 inhibitors whose $\mathrm{IC}_{50}$ 
values ranged from $0.34 \mathrm{nM}$ to $1.2 \mathrm{mM}$. The 3-D pharmacophore models are characterized by at least one hydrogen bond acceptor site and 2-3 hydrophobic sites and demonstrate very good correlation between the predicted and experimental IC $\mathrm{I}_{50}$ values.

Structure-activity relationships for 120 insecticidal DDT-type molecules including diaryl nitropropanes (Prolan analogs), diaryl trichloroethane and other DDT isosters, collected from different literature sources, to Musca dornestica, were analysed by regression analysis (RA) and a neural network model $(\mathrm{NN})^{71}$. The steric factors were reported extremely important to the activity of all the DDT-type analogs. The lipophilicity was also found to be important for the groups, because it facilitates delivery of these neurotoxicants to the site of action in the nerve. On the basis of training results, the NNs proved to give better results than a regression analysis technique and the most accurate predictions. To describe the role of each of the descriptors, a new method based upon the estimation of the connection weights, the identification and the rationalisation of the residuals was suggested.

\section{QSAR for toxicity prediction}

In addition to preliminary screening for minimal requirement as pesticides, toxicity of compounds is also tested in experiments with animals. As a result of this screening almost $90 \%$ of compounds are rejected due to low efficiency or high toxicity. Toxicological testing include uptake by inhalation or through skin. Toxicological tests include investigation of the effect of active substance, administered continuously in small doses over a longer period (e.g. 2 years) on experimental animals of several species including rats, birds, fishes and bees etc. Several successful QSARs for toxicity have attracted the researchers to investigate the relationship of structural properties with toxicity.

A hierarchical QSAR approach was applied for the prediction of acute aquatic toxicity where the chemical structures were encoded into molecular descriptors by an automated, seamless procedure available within the OpenMolGRID system ${ }^{72}$. Various linear and nonlinear regression techniques were used to obtain stable and thoroughly validated QSARs for toxicity. The final model was developed by a counter propagation neural network coupled with genetic algorithms for variable selection. Among the different techniques tested, the GA/CPANN combination proved suitable for the development of ecotoxicological QSARs.

Toxicities of ten organophosphorus (OP) insecticides were measured against midge larvae (Chirononzus viparius) under varying temperature and $\mathrm{pH}$ conditions and a series of unidimensional parameters and multidimensional models were used to describe the changes in toxicity ${ }^{73}$. $\operatorname{LogK}$, was able to explain about $40-60 \%$ of the variability in response data for aqueous exposures while molecular volume and aqueous solubility were less predictive. Likewise, the linear solvation energy relationship (LSER) model only explained $40-70 \%$ of the response variability, suggesting that factors other than solubility were most important for producing the observed response. Molecular connectivity was the most useful for describing the variability in the response. Molecular connectivity was a better tool than LSER or the unidimensional variables to explain the steric fitness of OP insecticides which was crucial to the toxicity.

In another study, topological indices were used in the prediction of the acute toxicity (intraperitoneal and oral $\mathrm{LD}_{50}$ ) of organophosphorus pesticides on rats ${ }^{74}$. Models with six variables for the prediction of $\mathrm{LD}_{50}$-i.p and eight variables for $\mathrm{LD}_{50}$-oral were selected. External group and cross-validation by use of leave- $n$-out tests were also performed in order to assess the stability and the prediction performance of the selected topological models. 
A QSAR study was performed on a set of organophosphorus compounds to reveal structural and quantum-chemical features influencing the toxic effect and the properties derived from the topological analysis of the electron density were used to model the toxicity data $^{75}$. A multiple linear regression analysis in conjunction with genetic algorithm was used in the study, followed by subsequent validation of the results. Obtained QSAR models were found beneficial for virtual screening of toxicity for new compounds of interest. Frequency calculations were performed after full geometry optimization. Ab initio wave functions were also obtained for further analysis and evaluation of quantum topological properties of target molecules.

Devillers $^{76}$ derived Quantitative structure-toxicity relationship (QSTR) models for estimating the acute oral toxicity of organophosphorus pesticides to male and female rats. The 51 chemicals of the training set and the nine compounds of the external testing set were described by means of autocorrelation vectors encoding lipophilicity, molar refractivity, $\mathrm{H}$ bonding acceptor ability (HBA) and $H$-bonding donor ability (HBD) of the molecules. A feature selection was employed for selecting the most relevant autocorrelation descriptors. A PLS regression analysis and an artificial neural network (ANN) were used for deriving models accounting for the sex of the organisms in the estimation of the toxicity of pesticides. The best results were obtained with an ANN model trained with the back-propagation and conjugate gradient descent algorithms. The root mean square residual (RMSR) values for the training set and the external testing set were 0.29 and 0.26 , respectively.

A study for the development of quantitative structure-activity relationships (QSARs) of 75 organophosphorus and carbamate pesticides for the toxicity to rainbow trout Onchorhyncus mykiss, was reportedly done ${ }^{77}$ for which the toxicity data were obtained from an openly available toxicological database and were selected to be representative of a single endpoint. QSAR models were developed using multiple linear regression and partial least-squares analyses after calculation of descriptors. Following the removal of a small number of outliers, predictive QSARs were developed on small numbers of mechanistically relevant descriptors. Applying mechanistic knowledge to the development of QSAR further improved predictivity and the effect of organic phosphorus pesticides on marine micro-alga was discussed through the QSAR model which reflected appropriate predicted toxic effects of different organic phosphorus pesticides ${ }^{78}$.

\section{QSAR for biodegradability prediction}

Quantitative structure-biodegradability relationships (QSBRs) relate the molecular structure of compounds to biological degradability and help in prediction of environmental fate. Thus it is not surprising that there is an increase in interest in QSBRs. The development of QSBRs has been relatively slow compared with proliferation of QSARs because of the nature of the biodegradability endpoint. QSBR is very complex because of environmental conditions and bioavailability of the chemical. The high complexity of microbial degradation process as well as great variety of interactions makes it difficult to interpret the results from biodegradability experiments.

Mechanistic approaches have been used to derive the QSAR models for microbial degradation of organic compounds ${ }^{79}$ while the biological degradability can be predicted with several programs that can learn from examples and can construct decision trees followed by construction of equations ${ }^{80}$. The main emphasis is given on the fact that contrary to the statistical methods, machine learning tools present the information in a compact and easily understandable manner which can help in the identification of key properties of chemicals that are important for assessing biodegradation. 
A three-parameter model including molecular average polarizability $(\alpha)$, entropy $(S \Theta)$, and molar heat capacity at constant volume $(\mathrm{CV \theta})$ were established for $\mathrm{Kb}$ prediction. Structural and thermodynamic parameters of 16 chloro-phenol compounds in water solution were calculated and fully optimized by using Onsager model in self-consistent reaction field (SCRF). These quantum chemical parameters were used as theoretical descriptors to correlate with the experimental biodegradation rate constant $(\mathrm{Kb})$ of these compounds by stepwise multiple linear regression $^{81}$.

Okey and Stensel developed QSBR procedure for aromatic xenobiotic degradation by unacclimated bacteria and acclimation was observed to be the function of many uncontrollable factors which includes the tendency of a organic to be toxic, its concentration, temperature, moisture and presence of other substrates ${ }^{82}$.

The multilayer perceptron (MLP) which is the application of the principal neural network architecture, have been developed for obtaining sufficient quantitative structurebinding relationships for a dataset of 17 barbiturates as guests complexing to $\alpha$ - and $\beta$-cyclodextrins ${ }^{83}$ and the results compared to that of earlier study that investigated the same problem using multiple regression analysis ${ }^{84}$. A series of new and improved algorithms were examined for training the MLP networks. The proposed methods led to substantial gain in both the prediction ability and the computation speed of the resulting models ${ }^{85}$.

\section{Future challenges}

The past and recent developments in understanding molecular action of DDT, computational chemistry and proteomics has provided a good platform for accelerating computer aided pesticide design, particularly DDT analogues based organochlorine pesticide. The challenge remains in integrating the QSAR, QSTR and QSBR models for a common set of molecules. Also, the results need to be validated with in vitro and in vivo models. When these challenges will be met, it may end up the row over ban and calling back of DDT and will provide a good replacement of DDT with economical viability, regarding usage in disease control programmes, without posing serious threat to ecosystem.

\section{Acknowledgement}

The financial assistance provided to Ms. Vandana Saini as Junior Research Fellowship by CSIR, Govt. Of India, New Delhi is acknowledged with thanks.

\section{References}

1. Coats J R, Environmental Health Perspectives, 1990, 87, 255-262.

2. U.S. E.P.A., http://www.epa.gov/pesticides/about/types.htm 2002

3. Bate R, http://fightingmalaria.org/pdfs/HPO_DDT.pdf 2007.

4. $\quad$ Van den Berg H, Environ Health Perspect., 2009, 117(11), 1656-1663.

5. Service M W, In Ecological Effects of Pesticides, Perring F H and Mellanby K, Eds., New York: Academic Press; 1977.

6. Mitra J and Raghu K, Environ Pollut., 1989, 61(2), 157-170;

DOI: 10.1016/0269-7491(89)90033-X. ISSN: 0269-7491

7. NPIC, National Pesticide Information Centre, http://ace.orst.edu/info/nptn 2000.

8. Curtis K, In Casarett \& Doull's Toxicology: The Basic Science of Poisons, $7^{\text {th }}$ Edition, 2007.

9. Attaran A, Donald R R, Chris F C and Wenceslaus L K, Nature Medicine, 2000, 6(7), 729-731; DOI:10.1038/77438

10. Krieger N, Wolff M S, Hiatt R A, Rivera M, Vogelman J and Orentreich N, $J$ Natl Cancer Inst., 1994, 86(8), 589-599; DOI:10.1093/jnci/86.8.589 
11. Schecter A, Toniolo P, Dai L C, Thuy L T B and Wolff M S, Arch Environ Contam Toxicol., 1997, 33(4), 453-456; DOI:10.1007/s002449900276

12. Hunter D J, Hankinson S E, Laden F, Colditz G A, Manson J A E, Willet W C, Speizer F E and Wolff M S, N Engl J Med., 1997, 337(18), 1253-1258.

13. López-Carrillo L, Blair A, López-Cervantes M, Cebrián M, Rueda C, Reyes R, Mohar A and Bravo J, Cancer Res., 1997, 57(17), 3728-3732.

14. Moysich K B, Shields P G, Mendola P, Freudenheim J L, Schisterman E F, Vena J E, Kostyniak P, Greizerstein H, Marshall J R, Graham S, Freudenheim J L and Ambrosone C B, Cancer Epidemiol Biomarkers Prev., 1998, 7, 181-188.

15. Zheng T, Holford T R, Mayne S T, Ward B, Carter D, Owens P H, Dubrow R, Zahm S H, Boyle P, Archibeque S and Tessarr J, Am J Epidemiol., 1999, 150(5), 453-458.

16. Van't Veer P, Lobbezoo I E, Martín-Moreno J M, Guallar E, Gómez-Aracena J, Kardinaal A F, Kohlmeier L, Martin B C, Strain J J, Thamm M, Zoonen P V, Baumann B A, Huttunen J K and Kok F J, Brit Med J., 1997, 315(7100), 81-85.

17. Helzlsouer K J, Alberg A J, Huang H Y, Hoffman S C, Strickland P T, Brock J W, Burse V W, Needham L L, Bell D A, Lavigne J A, Yager J D and Comstock G W, Cancer Epidemiol Biomarkers Prev., 1999, 8, 525-532.

18. Longnecker M P, Rogan W J and Lucier G, Annu Rev Pub Health, 1997, 18, 211-244.

19. Baris D, Zahm S H, Cantor K P and Blair A, Occup Environ Med., 1998, 55(8), 522-527; DOI:10.1136/oem.55.8.522

20. Gladen B C and Rogan W J, Am J Pub Health, 1995, 85(4), 504-508.

21. Goodman C A, Coleman P G and Mills A J, Lancet, 1999a, 354(9176), 378-385; http://dx.doi.org/10.1016/S0140-6736(99)02141-8

22. Goodman C A and Mills A J, Health Policy Planning, 1999b, 14(4), 301-312.

23. Gallup J L and Sachs J D, The Economic Burden of Malaria (Harvard Center for International Development), 1998, http://www.hiid.harvard.edu/pub/other/mal wb.pdf

24. Rengaraj R, Gunasekaran K, Muthukumaravel S, Kothandapani B and Purusothaman J, In silico Biology, 2007, 7, 0029.

25. Perry A, Yamamoto I, Ishaaya I and Perry R, In Insecticides in Agriculture and Environment: Retrospects and Prospects, Springer-Verlag, Berlin, Heidelberg, 1998.

26. Martinez-Torres D, Chandre F, Williamson M S, Darriet F, Berge J B, Devonshire AL, Guillet P, Pasteur N and Pauron D, Insect Mol Biol., 1998, 7(2), 179-184; DOI: $10.1046 / \mathrm{j} .1365-2583.1998 .72062 . x$

27. Jessell T M, Kandel E R and Schwartz J H, Principles of Neural Science (4 ${ }^{\text {th }}$ Ed.). McGraw-Hill., New York, 2000, 154-69.

28. Bertil H, Ion Channels of Excitable Membranes ( $3^{\text {rd }}$ Ed.), Sunderland, Mass, Sinauer., 2001, 73-77. ISBN 0-87893-321-2.

29. Catterall W A, Neuron, 2000m, 26(1), 13-25; http://dx.doi.org/10.1016/S0896-6273(00)81133-2

30. Hille B, J Gen Physiol., 1975, 66(5), 535-560; DOI:10.1085/jgp.66.5.535

31. Davies T G E, Field L M, Usherwood P N R and Williamson M S, IUBMB Life, 2007, 59(3), 151-162; DOI:10.1080/15216540701352042

32. Payandeh J, Scheuer T, Zheng N and Catterall W A, Nature, 2011, 475(7356), 353-358; DOI:10.1038/nature10238.

33. McCusker E C, Bagnéris C, Naylor C E, Cole A R, D'Avanzo N, Nichols C G and Wallace B A, Nat Commun., 2012, 3, 1102; DOI:10.1038/ncomms2077

34. PDB, Protein Data Bank,2013, www.rcsb.org

35. Reiss T, Trends Biotechnol., 2001, 19(12), 496-499;

DOI:10.1016/S0167-7799(01)01811-X 
36. Dean P M and Zanders E D, Biotechniques, 2002, Suppl(28-33).

37. Tice C M, Pest Manag Sci., 2001, 57(1), 3-16;

DOI: $10.1002 / 1526-4998(200101) 57: 1<3:: A I D-P S 269>3.0 . C O ; 2-6$

38. Bordas B, Komíves T and Lopata A, Pest Manag Sci., 2003, 59(4), 393-400;

DOI: $10.1002 /$ ps.614

39. Walters W P, Stahl M T and Murcko M A, Drug Discov Today, 1998, 3(4), 160-178; http://dx.doi.org/10.1016/S1359-6446(97)01163-X

40. Rester U, Curr Opin Drug Discov Devel., 2008, 11(4), 559-568.

41. Rollinger J M, Stuppner H and Langer T, Prog Drug Res., 2008, 65(211), 213-249.

42. Bradbury S, Toxicol Lett., 1995, 79(1-3), 229-237;

http://dx.doi.org/10.1016/0378-4274(95)03374-T

43. Bradbury S P, SAR QSAR Environ Res., 1994, 2(1-2), 89-104;

DOI:10.1080/10629369408028842

44. McKinney J D, Richard A, Waller C, Newman M C and Gerberick F, Toxicol Sci., 2000, 56(1), 8-17; DOI:10.1093/toxsci/56.1.8

45. Yang H Z, Nishimura M, Nishimura K, Kuroda S and Fujita T, Pest Biochem Physiol., 1987, 29(3), 217-232; http://dx.doi.org/10.1016/0048-3575(87)90152-0

46. Fatemi M H, Abraham M H and Haghdadi M, SAR QSAR Environ Res., 2009, 20(5-6), 453-465; DOI:10.1080/10629360903278776

47. Zakarya D, Boulaamail A, Larfaoui E M and Lakhlifi T, SAR QSAR Environ Res., 1997, 6(3-4), 183-203; DOI:10.1080/10629369708033251

48. Hansch C and Fujita T, J Am Chem Soc., 1964, 86(8), 1616-1626;

DOI: $10.1021 / \mathrm{ja} 01062 \mathrm{a} 035$

49. Free S M and Wilson J W, J Med Chem., 1964, 7(4), 395-399;

DOI:10.1021/jm00334a001

50. Katritzky A R and Lobanov V S, CODESSA: http://www.semichem.com/codessa/

51. Tetko I V, Gasteiger J, Todeschini R, Mauri A, Livingstone D, Ertl P, Palyulin VA, Radchenko E V, Zefirov N S, Makarenko A S, Tanchuk V Y and Prokopenko V V, $J$ Comput Aid Mol Des., 2005, 19(6), 453-463; DOI:10.1007/s10822-005-8694-y

52. Stuper A J and Jurs P C, J Chem Inf., 1976, 16(2), 99-105; DOI:10.1021/ci60006a014

53. Shi M, Tong W, Fang H, Xie Q, Hong H, Perkins R, Wu J, Tu M, Blair R M, Branham W S, Waller C, Walker J and Sheehan D M, SAR QSAR Environ Res., 2002, 13(1), 69-88; DOI:10.1080/10629360290002235

54. Rogers D and Hopfinger A J, J Chem Inf Comput Sci., 1994, 34, 854-866;

DOI:10.1021/ci00020a020

55. Clark D E and Westhead D R, J Comput Aided Mol Des., 1996, 10(4), 337-358; DOI:10.1007/BF00124503

56. So SS and Karplus M, JMed Chem., 1996, 39(7), 1521-1530; DOI:10.1021/jm9507035

57. Zheng W and Tropsha A, J Chem Inf Comput Sci., 2000, 40, 185-194.

58. Richon A B and Young S S, http://www.netsci.org/Science/Compchem/feature19.html

59. Dudek A Z, Tomasz A and Gálvez J, Combinatorial Chemistry High Throughput Screening, 2006, 9(2), 213-228; DOI:10.2174/138620706776055539

60. Verma J, Khedkar V M and Coutinho E C, Curr Topics Med Chem., 2010, 10(1), 95-115.

61. Andrade C H, Pasqualoto K F, Ferreira E I and Hopfinger A J, Molecules, 2010, 15, 3281-3294; DOI:10.3390/molecules 15053281

62. Vedani A and Dobler M, J Med Chem., 2002, 45(11), 2139-2149; DOI:10.1021/jm011005p

63. Vedani A, Dobler M and Lill M A, J Med Chem., 2005, 48(11), 3700- 3703. 
64. Auer C M, Nabholz J V and Baetcke K P, Environ Health Perspect., 1990, 87, 183-197.

65. Verhaar H J M, Rorije E, Borkent H, Seinen W and Hermens J L M, Environ Tox Chem., 1996, 15(6), 1011-1018; DOI:10.1002/etc.5620150625

66. $\quad$ Singh A K, SAR QSAR Environ Res., 2001, 12(3), 275-295;

DOI: $10.1080 / 10629360108032917$

67. Ehrich M, Correll L and Veronesi B, Fund Appl Toxicol., 1997, 38, 55-63.

68. Clothier B and Johnson M K, Biochem J., 1980, 185(3), 739-747.

69. Jinsong Z, Bin W, Zhaoxia D, Xiaodong W, Lingren K and Liansheng W, Chin Sci Bull., 2004, 49(3), 240-245; DOI:10.1007/BF03182805

70. Yazal E J, Rao S N, Mehl A and Slikker W, Toxicological Sci., 2001, 63(2), 223-232; DOI:10.1093/toxsci/63.2.223

71. Cronin M T D and Dearden J C, Quant Struct-Act Relat., 1995, 14(1), 1-7;

DOI:10.1002/qsar.19950140102

72. Mazzatorta P, Smiesko M, Piparo E L and Benfenati E, J Chem Inf Model., 2005, 45(6), 1767-1774; DOI:10.1021/ci0502471

73. Landrum P F, Fisher S W, Hwang H and Hickey J, SAR QSAR Environ Res., 1999, 10(5), 423-450; DOI:10.1080/10629369908039110

74. Domemnech R G, Elbal P A, Bolas G, Bueno Mari R, Chorda-Olmos F A, Delacour S A, Mourin M C, Vidal A and Galvez J, SAR QSAR Environ Res., 2007, 18(7-8), 745-755; DOI:10.1080/10629360701698712

75. Paukku Y and Hill G, Int J Quantum Chem., 2012, 112(5), 1343-1352;

DOI:10.1002/qua.22995

76. Devillers J, SAR QSAR Environ Res., 2004, 15(5-6), 501-510; DOI:10.1080/10629360412331297443

77. Saldana J B M and Cronin M T D, Pest Manage Sci., 2006, 62(9), 819-831; DOI: $10.1002 /$ ps. 1233

78. Li Ma, Wang T and Liu X, Int Sympos Wat Resour Environ Protec., 2011, 3, 2025- 2028; DOI:10.1109/ISWREP.2011.5893658

79. Damborsky J, SAR QSAR Environ Res., 1996, 5(1), 27-36; DOI:10.1080/10629369608031704

80. Kompare B, Wat Sci Tech., 1998, 37(8), 9-18.

81. Yi-Jun C, Zun-Yao W, Liang M and Shi-Xiang, Chinese J Struct Chem., 2010, 29(6), 895-899.

82. Okey R W, Stensel H D, Water Environ Res., 1993, 65(6), 772-780;

DOI:10.2175/WER.65.6.10

83. Lukovits I and Lopata A, J Med Chem., 1980, 23(4), 449-459;

DOI: $10.1021 / \mathrm{jm} 00178 \mathrm{a} 018$

84. Loukas Y L, Int J Pharm., 2001, 226(1-2), 207-211;

DOI:10.1016/S0378-5173(01)00779-7

85. Viswanadhan V N, Mueller G A, Basak S C and Weinstein J N, J Chem Inf Comp Sci., 2001, 41(3), 505-511. 